\title{
ARTIGOS
}

Submetido 22.12.2014. Aprovado 22.04.2015

Avaliado pelo processo de double blind review. Editor Científico: Mateus Canniatti Ponchio

DOI: http://dx.doi.org/10.1590/So034-759020160106

\section{CRITÉRIOS DE ESTRATIFICAÇÃO E COMPARAÇÃO DE CLASSIFICADORES SOCIOECONÔMICOS NO BRASIL}

\author{
Socioeconomic stratification criteria and classification tools in Brazil \\ Criterios de estratificación y comparación de clasificadores socioeconómicos \\ en Brasil
}

\section{RESUMO}

Este estudo tem por propósito comparar conceitual e metodologicamente cinco classificadores para a estratificação socioeconômica da sociedade brasileira e mensurar os trade-offs de erros de classificação entre eles. Com base nos algoritmos de classificação de cada critério, classificamos os 55.970 domicílios que compõem a amostra representativa da pesquisa de orçamentos familiares (POF), realizada pelo Instituto Brasileiro de Geografia e Estatística (IBGE). Os resultados obtidos permitem afirmar que o classificador de máxima verossimilhança foi o que apresentou a melhor performance em explicar o nível de consumo das famílias brasileiras por estrato socioeconômico, seguido do classificador bayesiano adaptável, da Associação Brasileira de Empresas de Pesquisa (ABEP) simplificado, do ABEP antigo e da Secretaria de Assuntos Estratégicos (SAE). Os três primeiros classificadores estão sustentados no conceito da renda permanente/ riqueza do domicílio, incorporando os dois primeiros uma importante inovação: classificar um domicílio levando em conta sua localização geográfica e a composição familiar. Esses novos classificadores possibilitam aos pesquisadores e gestores de marketing segmentar e estudar mercados baseados em critério válido, fidedigno e confiável de estratificação socioeconômica.

PALAVRAS-CHAVE | Segmentação de mercado, classe socioeconômica, status socioeconômico, classificadores socioeconômicos, mercados emergentes.

\section{ABSTRACT}

The purpose of this study was to compare the conceptual and methodological features of five classification algorithms used to produce socioeconomic stratifications of the Brazilian society, and to measure misclassification tradeoffs between them. We applied these five algorithms to classify the 55,970 households covered in the survey of household budgets (Pesquisa de Orçamentos Familiares [POF]) conducted by Brazilian Institute of Geography and Statistics (Instituto Brasileiro de Geografia e Estatística [IBGE]). Our results allow us to conclude that maximum-likelihood classifier had the best performance in explaining Brazilian families' consumption patterns across the socioeconomic strata, followed by the adaptive Bayesian, simplified ABEP, old $A B E P$, and SAE algorithms. The first three classifiers rely on the concept of permanent income, while the first two incorporate an important innovation: classifying a household by considering its geographic location and family composition, the latter defined by the number of adults and minors living in the household. These new classifiers allow researchers and marketers to segment and study markets based on a valid, unbiased, and reliable criterion of socioeconomic stratification.

KEYWORDS / Market segmentation, socioeconomic class, socioeconomic status, socioeconomic classifier, emerging markets.

\section{RESUMEN}

Este estudio tiene como propósito comparar conceptual y metodológicamente cinco clasificadores para la estratificación socioeconómica de la sociedad brasileña y medir los trade-offs de errores de clasificación entre ellos. Con base en los algoritmos de clasificación de cada criterio, clasificamos los 55.970 domicilios que componen la muestra representativa de la encuesta de presupuestos familiares (Pesquisa de Orçamentos Familiares [POF]), realizada por el Instituto Brasileño de Geografía y Estadística (Instituto Brasileiro de Geografia e Estatística [IBGE]). Los resultados obtenidos permiten afirmar que el clasificador de máxima verosimilitud fue el que presentó el mejor desempeño en explicar el nivel de consumo de las familias brasileñas por estrato socioeconómico, seguido del clasificador bayesiano adaptable, del ABEP simplificado, del ABEP antiguo y de la SAE. Los tres primeros clasificadores están sustentados en el concepto del ingreso permanente/riqueza del domicilio, incorporando los dos primeros una importante innovación: clasificar un domicilio teniendo en cuenta su localización geográfica y la composición familiar. Estos nuevos clasificadores posibilitan a los encuestadores y gestores de marketing segmentar y estudiar mercados basados en criterio válido, fidedigno y confiable de estratificación socioeconómica.

PALABRAS CLAVE / Segmentación de mercado, clase socioeconómica, estatus socioeconómico, clasificadores socioeconómicos, mercados emergentes. 


\section{INTRODUÇÃO}

Estratificação socioeconômica tem sido um tema amplamente debatido e utilizado não apenas em marketing, mas em inúmeros outros campos de conhecimento, como medicina, educação, psicologia, desenvolvimento econômico, entre outros. Kamakura e Mazzon (2013a, 2013b) apresentaram e discutiram amplamente esses usos e os fundamentos conceituais e metodológicos da estratificação socioeconômica (ESE). Propuseram um novo critério calcado no conceito de renda permanente (Friedman, 1957) e no uso da modelagem por classes latentes ordinais (Vermunt \& Magdison, 2010). Contudo, ainda permanece na literatura uma lacuna relacionada com a mensuração da precisão comparada de instrumentos (classificadores) para identificar em qual estrato socioeconômico se classifica uma família ou consumidor. Assim, este estudo visa comparar a performance de classificadores de ESE para fins de segmentação do mercado brasileiro, contrapondo a decisão de escolha entre simplicidade no processo de coleta de dados e erros de classificação de consumidores por diferentes classificadores disponíveis no Brasil. Pretendemos, ainda, mostrar diferenças no perfil de consumo dos consumidores segundo cada classificador, de grande relevância para o desenvolvimento de pesquisas e para a prática do marketing.

Como subsídio à discussão a respeito dos classificadores socioeconômicos, apresentamos uma síntese da relevância da estratificação de uma sociedade, sob uma perspectiva tanto acadêmica quanto empresarial. Para isso, tomamos por base os estudos realizados por Kamakura e Mazzon (2013a, 2013b), que mostram o crescimento de uma classe média com poder de compra mais elevado, como também o esforço realizado para atingir melhor estilo de vida por meio do consumo de produtos e serviços de maior status social (Cui \& Song, 2009; Neri, 2011), impulsionando o crescimento da demanda das famílias por bens e serviços com maior valor agregado (Senauer \& Goetz, 2003). Assim, utilizamos o conceito de ESE com o propósito de relacionar o nível socioeconômico das famílias com os seus volumes e perfis de consumo. Essa medida desempenha papel importante em marketing por refletir valores, atitudes, normas sociais, estilos de vida e padrões de consumo diferenciados por estrato socioeconômico. Mittal, Holbrook, Sharon, Raghubir, e Woodside (2008) argumentam que consumidores, com o propósito de ser aceitos e sentir que pertencem a determinado grupo social, tendem a adotar comportamentos visíveis de consumo compatíveis com o status socioeconômico desse segmento. A melhor forma de atendê-los relaciona-se com estratégias de marketing diferenciadas segundo o trinômio segmentação, escolha de grupos-alvo e posicionamento de marketing (Wedel \& Kamakura, 2001).
Há pelo menos cinco décadas, o marketing faz uso da estratificação socioeconômica para segmentar o mercado (Bauer, Cunningham, \& Wortzel, 1965), formular estratégias de comunicação e mídia (Bass, Pessemier, \& Tigert, 1969; Rich \& Jain, 1968), avaliar estratégias de preço (Frank \& Massy, 1965), decisões de compra (Williams, 2002), experiências vivenciadas no consumo de produtos (Dahl \& Moreau, 2007), desejo de aquisição de tipos de produtos (Rucker \& Galinski, 2008) e atitudes em relação a produtos globais e locais (Steenkamp, Jong, \& Baumgartner, 2010). Kamakura e Mazzon (2013a, 2013b) mostraram inúmeros critérios existentes em dezenas de países para medir o nível socioeconômico calcados em variáveis como renda corrente, ocupação, escolaridade, características do imóvel em que a família reside, posse de bens, entre outras. Por exemplo, na Argentina o critério é baseado em uma pontuação arbitrária de três variáveis: ocupação e educação do chefe da família e posse de determinados bens de consumo. No Chile, consideram-se ocupação e educação do chefe da família, renda familiar, local e características da residência e automóveis possuídos. A European Society for Opinion and Marketing Research (ESOMAR) estabeleceu um critério calcado na escolaridade e ocupação da pessoa que tem a maior renda na casa (Schmeichel, Corrales, \& Barberena, 1999; Urquijo \& Lobl, 2003).

A principal crítica aos critérios existentes de estratificação socioeconômica relaciona-se com sua validade interna (Corrales, Barbarena, \& Schmeichel, 2006), levando Bollen, Glanville, e Stecklov (2001, p. 153) a afirmar que há "falta de consenso sobre o significado conceitual e sobre a mensuração do status socioeconômico". A American Psychological Association instituiu um grupo permanente de pesquisa e conclamou seus associados a estudar o tema Socioeconomic Status (Saegert et al., 2006). 0 governo brasileiro (Brasil, 2012) e o dos EUA (Blank, 2010) constituíram forças-tarefa visando identificar e quantificar os estratos socioeconômicos das respectivas sociedades. Revistas de marketing publicaram recentemente (International Journal of Research in Marketing, 2013) ou estão em processo de publicar (Marketing Science e Customer Needs and Solutions) edições especiais sobre a nova classe de consumidores nas economias emergentes.

No Brasil, existem três critérios de classificação socioeconômica: (1) elaborado pela Secretaria de Assuntos Estratégicos (SAE) da Presidência da República (Brasil, 2012), voltado para a avaliação de políticas públicas direcionadas à classe média e calcado no conceito da renda corrente familiar per capita; esse critério pode ser útil para políticas governamentais, mas é de utilidade limitada para marketing; (2) Associação Brasileira de Empresas de Pesquisa (ABEP) antigo (ABEP, 2011), cuja vigência foi até 2014 , focado para uso em marketing, calcado na educação do chefe da família e quantidades possuídas de oito tipos 
de bens duráveis e do número de empregados mensalistas no domicílio; e (3) o critério descrito por Kamakura e Mazzon (2013a, 2013b), concebido para uso primordial em marketing, baseado no conceito teórico de renda permanente e na modelagem de classes latentes ordinais.

A partir desse novo critério, foram desenvolvidos três classificadores, adotados pela ABEP a partir de 2015. Esses novos classificadores foram elaborados com base no critério de Kamakura e Mazzon (2013a) para atender às necessidades de diferentes usuários, dependendo da forma de coleta dos dados. $O$ primeiro e mais completo classificador, denominado "ABEP novo", foi operacionalizado pelo processo de verossimilhança condicional com informação completa, composto por até 35 itens envolvendo anos de escolaridade do responsável pela família, renda bruta mensal familiar, número de dormitórios e de banheiros, acesso a serviços de abastecimento de água e coleta de esgoto, pavimentação da rua, quantidade de empregados mensalistas no domicílio e quantidade possuída de 27 bens duráveis, ajustado por quatro covariáveis: região geográfica, tipo de localização do domicílio e quantidade de adultos e menores presentes na moradia. Um segundo classificador, denominado "ABEP adaptável”, foi instrumentalizado por um classificador bayesiano com 16 indicadores entre os que compõem o modelo anterior $3 a$, também ajustado para classificar uma família levando em consideração as quatro covariáveis. Finalmente, o "ABEP simplificado", representado por um classificador composto por 15 variáveis, desenvolvido para uso específico em locais com dificuldade ou sem acesso à internet - o que impossibilitaria o emprego dos classificadores de verossimilhança condicional e bayesiano adaptável. Ressalte-se que esse classificador simplificado apresenta uma forte limitação: não leva em consideração, na classificação socioeconômica, a região geográfica em que reside a família, o tipo de domicílio e a composição familiar, sendo a classificação única para o Brasil como um todo.

Como este estudo pretende suprir a lacuna de avaliação da performance comparativa desses cinco classificadores, é importante estabelecer a distinção entre esse conceito e o de critério de classificação. Critério de classificação socioeconômica atenta para quatro características: base teórica emulada (renda corrente ou renda permanente); técnica estatística empregada na modelagem; definição do número de estratos e limites que separam uma classe socioeconômica de outra. 0 termo classificador socioeconômico refere-se especificamente a um algoritmo estatístico que possibilita classificar um domicílio em um dos estratos socioeconômicos definidos por cada critério.

Devemos ressaltar que a análise comparativa dos resultados da implementação dos classificadores da SAE e da ABEP, antigo e novos - que resultaram nos cinco classificadores - não foi abordada nos estudos de Kamakura e Mazzon (2013a, 2013b). Essa comparação é importante e necessária, considerando que a estratificação das famílias deve ser consistente com a nova realidade socioeconômica do Brasil, especialmente em relação a quatro aspectos: a) existência de programas de transferência de renda implementados pelo governo federal e por alguns governos estaduais e municipais, que representam um aumento no orçamento familiar e na possibilidade de aquisição de produtos e serviços novos ou bens atuais em maior quantidade (Campello \& Neri, 2013); b) o crescimento da "nova classe média” brasileira, com maior facilidade de acesso ao crédito e melhor qualificação profissional do trabalhador (Brasil, 2012); c) o fato de o classificador ABEP antigo, assim como estratégias das empresas voltadas para o mercado consumidor, focarem especialmente os estratos de nível socioeconômico mais elevado, porque neles estava concentrado maior poder aquisitivo e maior dispêndio no consumo de bens e serviços. Atualmente, observa-se maior interesse das empresas em implementar estratégias de marketing diferenciadas para estratos de classes intermediárias e de menor poder aquisitivo (Deaton \& Muellbauer, 2009); d) auxiliar o pesquisador na decisão de risco assumido contrapondo os trade-offs de erro de classificação de famílias entre os diferentes classificadores. Assim, neste artigo, o propósito é complementar os estudos de Kamakura e Mazzon (2013a, 2013b) por meio da avaliação da performance comparada desses classificadores, identificando a que estratos socioeconômicos pertencem os consumidores e mensurando os respectivos erros de classificação incorridos, tomando-se por benchmark o classificador completo de verossimilhança condicional.

\section{CRITÉRIOS DE ESTRATIFICAÇÃO SOCIOECONÔMICA DA SOCIEDADE BRASILEIRA}

\section{Critério SAE}

Objetiva definir, para fins de política pública, o que é a classe média brasileira. Essa secretaria estabeleceu que o critério deveria estar fundamentado nas seguintes características: a) ser passível de implantação com informação disponível, objetiva e fidedigna; b) ser conceitual e metodologicamente sólido; c) ser facilmente compreendido por pessoas de diferentes graus de instrução (Brasil, 2012).

A SAE limitou o critério a uma variável, renda familiar corrente per capita. Selecionada a variável-chave, originada da Pesquisa Nacional por Amostra de Domicílios (PNAD), utilizou 
um critério de vulnerabilidade familiar para estabelecer limites superior e inferior da classe média, considerando o interesse desse órgão no aprimoramento de políticas públicas voltadas para essa classe. A partir da observação empírica dos movimentos de ascensão e queda de renda da população brasileira nos últimos anos, a SAE definiu o grau de vulnerabilidade de um domicílio à condição de pobreza - estabelecida como a renda corrente declarada per capita inferior a R\$140,00 mensais - em algum momento dos próximos cinco anos (Brasil, 2012). Tomando por base o grau de vulnerabilidade, dividiu a população brasileira em três grupos, com o propósito de maximizar a homogeneidade dentro de cada grupo, utilizando um critério denominado pola- rização. Estabelecidos os pontos de corte inferior e superior de cada classe socioeconômica - baixa, média e alta -, a Secretaria estabeleceu subdivisões dentro de cada classe, objetivando inclusive comparações com o critério da ABEP. Por meio dessa subdivisão, a SAE definiu três grupos componentes da classe baixa (extremamente pobre, pobre, mas não extremamente pobre, e vulnerável); três grupos para a classe média (baixa classe média, média classe média e alta classe média) e dois grupos para a classe alta (baixa classe alta e alta classe alta). Portanto, a estratificação da sociedade brasileira foi definida em oito grupos, os quais representam, para o ano base de 2009 e a preços de abril de 2012, a seguinte distribuição percentual:

Tabela 1. Tamanho dos estratos segundo o modelo SAE

\begin{tabular}{|c|c|c|c|c|c|}
\hline Estratos (ordem & \multicolumn{2}{|c|}{ Denominação } & Renda familiar per & Tamanho dos estratos & Tamanho dos estratos \\
\hline 1 & \multirow{3}{*}{ Baixa } & Extremamente pobre & Até 81 & 5 & 8,4 \\
\hline 2 & & $\begin{array}{l}\text { Pobre, mas não } \\
\text { extremamente pobre }\end{array}$ & Entre 81 e 162 & 10 & 19,2 \\
\hline 3 & & Vulnerável & Entre 163 e 291 & 19 & 17,5 \\
\hline 4 & Média & Baixa classe média & Entre 292 e 441 & 17 & 15,8 \\
\hline 7 & \multirow{2}{*}{ Alta } & Baixa classe alta & Entre 1.020 e 2.480 & 13 & 7,3 \\
\hline 8 & & Alta classe alta & Mais de 2.480 & 4 & 2,5 \\
\hline
\end{tabular}

Nota. Recuperado de Secretaria de Assuntos Estratégicos, Presidência da República, 2012.

Definida a classe média representando praticamente a metade da população brasileira, a SAE poderia captar a sua evolução temporal por alterações na renda domiciliar. Essa secretaria estimou para 2012 o tamanho da classe média em $54 \%$ da população (SAE, 2012), tendo ocorrido diminuição da classe baixa, em parte explicada por valores da renda per capita serem deflacionados por um índice de inflação, enquanto os salários estariam corrigidos pela inflação e por ganhos de produtividade.

\section{Critério Brasil (antigo, vigente até 2014)}

Em 1997, as entidades Associação Brasileira de Anunciantes (ABA), Associação Brasileira de Anunciantes/Associação Brasileira dos
Institutos de Mercado (Abipeme) e Associação Nacional de Empresas de Pesquisa de Mercado (ANEP) desenvolveram um estudo que resultou na proposição de um critério denominado Critério de Classificação Econômica Brasil (CCEB) (ABEP, 2011). A elaboração desse critério objetivou disponibilizar um sistema de pontuação proxy da capacidade de consumo de um domicílio localizado em regiões metropolitanas brasileiras, utilizando dados objetivos e de fácil coleta no campo. Em 2008, o Critério Brasil utilizava a metodologia da regressão estatística do logaritmo da renda corrente familiar declarada como função da quantidade possuída de itens de conforto doméstico e instrução do responsável pelo domicílio (ABEP, 2011). Esse critério, aqui denominado ABEP antigo, vigorou até dezembro de 2014, conforme tabela a seguir.

\section{Tabela 2. Tamanho dos estratos segundo o modelo ABEP antigo}

\begin{tabular}{c|c|c|c|c}
\hline Estratos (ordem decrescente & Denominação & Pontos & Tamanho dos estratos ABEP (em \%) & Tamanho dos estratos POF (em \%) \\
\hline 1 & A1 & Entre 42 e 46 & 0,9 & 0,1 \\
\hline 2 & A2 & Entre 35 e 41 & 4,1 & 1,5 \\
\hline 3 & B1 & Entre 29 e 34 & 8,9 & 4,4 \\
\hline 4 & B2 & Entre 23 e 28 & 15,7 & 11,3 \\
\hline 5 & C1 & Entre 18 e 22 & 20,7 & 19,3 \\
\hline 6 & C2 & Entre 14 e 17 & 21,8 & 23,6 \\
\hline 7 & D & Entre 8 e 13 & 25,4 & 32,9 \\
\hline 8 & E & Entre o e 7 & 2,6 & 6,9 \\
\hline
\end{tabular}

Nota. Recuperado de Associação Brasileira de Empresas de Pesquisa, 2011. 
Verifica-se que existe uma acentuada assimetria na distribuição dos tamanhos das classes, em que as três primeiras representam $13,9 \%$ dos domicílios das regiões metropolitanas, enquanto as três últimas correspondem a 49,8\% das moradias. Esse critério destaca as classes de maior poder aquisitivo ( $\mathrm{A}_{1} \mathrm{e} \mathrm{A} 2$ ), concentrando elevado número de domicílios nas classes de menor capacidade de compra.

\section{Novo critério Brasil (vigência a partir de 2015)}

Sob uma perspectiva metodológica, Kamakura e Mazzon (2013a) estabeleceram que esse novo critério deveria: a) estar calcado em uma sólida base conceitual, propiciada pelo conceito de renda permanente - que expressa a riqueza do domicílio e seu poder de compra -, dimensão essa fundamental para a segmentação do mercado consumidor; b) ser multidimensional, considerando variáveis que expressassem o status socioeconômico de uma família; c) ser não arbitrário na definição do número de classes socioeconômicas e na classificação de um domicílio em um dos estratos; d) ser robusto a missing data, muito comum em pesquisas sociais aplicadas, seja por impossibilidade ou por recusa do entrevistado fornecer o dado solicitado; e) ser flexível para trabalhar com subconjuntos de uma base comum de dados, possibilitando classificar e comparar distintas pesquisas, mesmo que usassem diferentes tipos de dados de um rol comum de variáveis; f) ser robusto para usar variáveis de diferentes métricas: nominais (por exemplo, forma pela qual o domicílio é abastecido por água e tipo de esgotamento sanitário); ordinais (por exemplo, instrução do chefe da família) ou de contagem e razão, por exemplo, quantidade de microcomputadores no domicílio ou renda corrente familiar; g) levar em conta diferenças regionais perceptíveis na realidade brasileira em termos de regiões e características da localidade do domicílio; h) considerar diferenças na composição familiar, já que necessidades de bens e serviços são específicas para distintos tipos de famílias. Para efeito de segmentação de mercado, características geográficas e de composição das famílias são imprescindiveis de serem consideradas, haja vista sua influência na escolha de produtos e serviços que serão por elas adquiridos. Pensando nesse conjunto de premissas, definiram que o modelo estatístico mais apropriado era o de classes latentes ordinais, cujas características podem ser vistas em Vermunt e Magidson (2010).

O passo inicial para a construção do modelo de Kamakura e Mazzon (2013a) consistiu na divisão da sociedade brasileira em 20 percentis, cada um representando $5 \%$ da população de domicílios, ordenados de modo decrescente no nível socioeconômico. Essa divisão em 20 partes iguais e monotonicamente decrescentes permitiria deslocar o foco estéril da discussão do quanto representa (tamanho) cada classe, para um propósito útil de possibilitar a análise da evolução do perfil de cada vintil nos indicadores de renda, escolaridade, utilização de serviços públicos essenciais, posse e quantidade de bens de conforto doméstico que caracterizam, em seu conjunto, o construto de renda permanente. Em seguida, Kamakura e Mazzon (2013a) analisaram diferenças no perfil demográfico dos vintis definidos pelo modelo de classes latentes ordinais e, como forma de validação do critério, no perfil de consumo de 21 categorias de bens e serviços da pesquisa de orçamentos familiares (POF) (IBGE, 2009), cujo consumo marginal foi ajustado pelas covariáveis composição familiar e localização do domicílio. Como segmentar o mercado em 20 partes não seria eficiente sob uma perspectiva gerencial, os vintis foram agrupados em um número menor de estratos. Para tanto, utilizaram a técnica Delphi, em que um grupo de experts avaliou o perfil de consumo de cada categoria de produto ou serviço. Da análise das diferenças estatísticas existentes nos níveis de consumo das 21 categorias, decidiram pela agregação dos vintis em sete estratos socioeconômicos, cujos tamanhos estimados pelo modelo de classes latentes encontram-se na Tabela 3, em que os estratos 1 e 2 correspondem aos respectivos vintis 1 e 2 ; o estrato 3 corresponde aos vintis 3, 4 e 5, e assim sucessivamente até o estrato 7, que corresponde aos vintis 18, 19 e 20.

\section{Tabela 3. Tamanho dos estratos segundo o modelo ABEP novo}

\begin{tabular}{c|c|c}
\hline $\begin{array}{c}\text { Estratos (ordem } \\
\text { decrescente }\end{array}$ & Denominação & $\begin{array}{c}\text { Tamanho dos estratos } \\
\text { POF(em \%) }\end{array}$ \\
\hline 1 & E1 & 2,8 \\
\hline 2 & E2 & 3,6 \\
\hline 3 & E3 & 15,1 \\
\hline 4 & E4 & 20,6 \\
\hline 5 & E5 & 20,6 \\
\hline 6 & E6 & 22,8 \\
\hline 7 & E7 & 14,5 \\
\hline
\end{tabular}

Nota. Adaptado de "Estratificação socioeconômica e consumo no Brasil", de W. A. Kamakura e J. A. Mazzon, 2013a, São Paulo: Blucher.

Verifica-se, pela Tabela 4, a existência de diferenças expressivas no perfil socioeconômico entre os estratos. Enquanto a renda familiar média nacional situa-se em $R \$$ 2.770,00 (a preços de 2009), a renda média corresponde a $\mathrm{R} \$ 17.603,00$ para o estrato 1 - de nível socioeconômico mais elevado -, decaindo para um valor médio de $\mathrm{R} \$ 673$, 00 para o estrato 7, o de menor nível socioeconômico. Número de banheiros no domicílio, cuja média nacional é de 1,3, no estrato 1 é de 3,2 banheiros, enquanto nos estratos 5, 6 e 7, é de um banheiro por domicílio. Tomando-se o indicador de penetração de mercado, no estrato 1 , observa-se que $95,1 \%$ das moradias têm pelo menos uma máquina de lavar roupa; nos estratos 6 e 7 , esse indicador corresponde a $22,2 \%$ e $3,9 \%$, respectivamente. 
Tabela 4. Perfil bruto da penetração de bens duráveis e serviços públicos nos sete estratos socioeconômicos do modelo ABEP novo de verossimilhança condicional

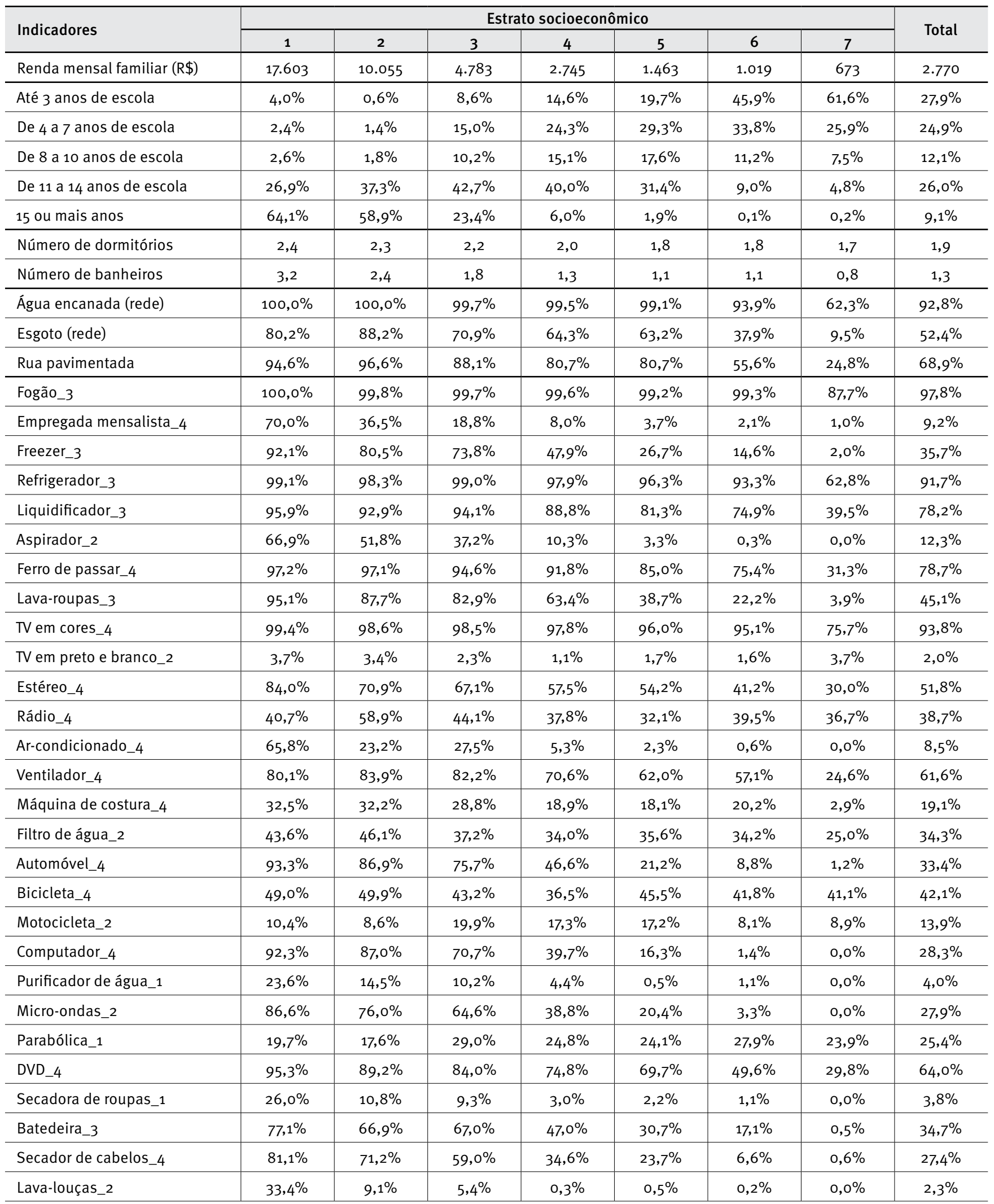

Nota. Adaptado de "Estratificação socioeconômica e consumo no Brasil”, de W. A. Kamakura e J. A. Mazzon, 2013a, São Paulo: Blucher. 
Tabela 5. Gasto médio anual por domicílio em cada estrato

\begin{tabular}{|c|c|c|c|c|c|c|c|c|}
\hline Alimentação no domicílio & 6.748 & 5.527 & 4.252 & 3.411 & 2.690 & 2.431 & 2.124 & 3.148 \\
\hline Alimentação fora do domicílio & 7.182 & 4.735 & 2.520 & 1.654 & 940 & 550 & 379 & 1.465 \\
\hline Bebidas & 1.068 & 952 & 690 & 515 & 374 & 269 & 241 & 448 \\
\hline Produtos para manutenção da casa & 7.068 & 3.864 & 2.406 & 1.317 & 850 & 617 & 480 & 1.356 \\
\hline Eletrodomésticos & 2.457 & 1.578 & 1.073 & 740 & 502 & 336 & 247 & 656 \\
\hline Vestuário & 5.467 & 3.296 & 2.309 & 1.549 & 985 & 643 & 450 & 1.353 \\
\hline Educação & 5.858 & 3.469 & 1.769 & 679 & 246 & 107 & 55 & 778 \\
\hline Viagens, recreação e cultura & 6.708 & 3.752 & 1.603 & 830 & 434 & 248 & 152 & 902 \\
\hline Fumo & 275 & 191 & 162 & 163 & 130 & 119 & 90 & 139 \\
\hline Uso pessoal & 504 & 202 & 120 & 63 & 33 & 20 & 13 & 66 \\
\hline Habitação e materiais de construção & 24.933 & 15.533 & 8.822 & 5.248 & 3.366 & 2.439 & 1.430 & 5.122 \\
\hline Serviços pessoais e profissionais & 8.810 & 4.122 & 1.959 & 684 & 321 & 179 & 80 & 949 \\
\hline Outras despesas & 8.125 & 5.103 & 2.475 & 1.344 & 606 & 383 & 229 & 1.305 \\
\hline Investimentos & 44.567 & 21.736 & 9.118 & 3.587 & 1.223 & 461 & 255 & 4.531 \\
\hline Média anual de gastos/domicílio & 170.392 & 98.614 & 54.150 & 30.578 & 17.981 & 12.249 & 8.134 & 30.438 \\
\hline
\end{tabular}

O processamento da base de dados da POF 2009 utilizando o classificador de verossimilhança condicional permitiu estruturar a Tabela 5 , relativa a valores de consumo de bens e serviços pelos diferentes estratos. Verifica-se, pelo montante médio anual de gastos por categoria de despesa e estrato socioeconômico, que, no estrato 1, esse valor foi de $R \$ 170.392,00$, enquanto no estrato 7 foi de $R \$ 8.134,00$, cerca de 21 vezes mais. Selecionando uma categoria de bem essencial - alimentação no domicílio -, verifica-se que a classe 1 apresenta um gasto médio anual de $R \$ 6.748,00$, enquanto a 7 , de $R \$ 2.124$, oo por ano. Em gastos com educação, o montante médio anual gasto pelo estrato 1 correspondeu a $R \$ 5.858,00$, enquanto no estrato 7, a $R$ \$ 55,00. Em alimentação, a proporção de gastos do estrato 1 em relação ao 7 foi de 3,2 vezes; em gastos com educação, essa proporção foi de 106,1. No caso de "bens supérfluos", como serviços pessoais e profissionais (manicure, cabeleireiro, advogado etc.), o gasto médio anual do estrato 1 foi de $R \$ 8.810,00$ por ano, ao passo que no estrato 7 representou $R \$ 80,00$, cerca de 110 vezes mais. Observa-se que, nas categorias de bens mais essenciais, a proporção de gastos dos estratos de nível socio- 
econômico mais elevado em relação aos de nível mais baixo é bastante inferior à de categorias de bens e serviços menos essenciais ou mais supérfluos. Vale dizer que, para um bem essencial, o consumo médio tende a ser menos diferenciado do que em relação a um bem supérfluo. Não obstante, mesmo para bens essenciais, a estratificação permite evidenciar diferenças significativas na quantidade consumida e na qualidade dos bens e marcas adquiridos.

\section{Classificadores de domicílios nos estratos socioeconômicos}

Para cada critério de estratificação socioeconômica, tem-se um algoritmo ou classificador que possibilita identificar em qual classe socioeconômica um domicílio é inserido.

O classificador SAE é definido pelos intervalos de renda per capita dos oito estratos constantes da Tabela 1 (Brasil, 2012). O classificador da ABEP com vigência até 2014 corresponde aos intervalos de pontos associados a cada um dos oito estratos especificados na Tabela 2 (ABEP, 2011).

O classificador ABEP novo (Kamakura \& Mazzon, 2013a) de máxima verossimilhança foi definido por 35 indicadores (Tabela 4) e quatro covariáveis - região geográfica, localização do domicílio e quantidade de adultos e menores de 18 anos moradores na casa. Esse classificador é robusto mesmo na presença de dados faltantes, não requerendo qualquer imputação arbitrária, por exemplo, pela média. Kamakura e Mazzon (2013a, 2013b) mostram que a função de verossimilhança condicional que define a probabilidade de um domicílio $i$ pertencer ao estrato s é calculada multiplicando-se as probabilidades condicionais para todos os $k$ indicadores disponíveis para esse domicílio, tal como apresentada abaixo:

$$
L\left\{Y_{i} / \Theta_{s} X_{j}\right\}=\prod_{k=1}^{K} \mathrm{p}\left(\mathrm{y}_{i k} \mid \Theta_{k s} \mathrm{X}\right)
$$

Considerando que o produto $\prod_{k=1}^{K}($ ) somente se aplica aos indicadores disponíveis para um domicílio $i$, a probabilidade a posteriori de que esse domicílio $i$ pertença ao estrato $s$ é calculada por meio da fórmula bayesiana, onde o numerador corresponde à verossimilhança condicional ao estrato $s$ e 0 denominador, à verossimilhança não condicionada, como apresentado abaixo:

$$
\tau_{i s}=\frac{L\left\{Y_{i} \mid \Theta_{s^{\prime}} X_{j}\right\}}{\sum_{s^{\prime}}^{S}=1^{\pi_{s}} L\left\{Y_{i} \mid \Theta_{s^{\prime}}, X_{j}\right\}}=\frac{\prod_{k=1}^{K} p\left(y_{i k} \mid \Theta_{k s^{\prime}} X_{j}\right)}{\sum_{s^{\prime}}^{S}=1^{\pi_{s}}, \prod_{k=1}^{K} p\left(y_{i k} \mid \Theta_{k s^{\prime}}, X_{j}\right)}
$$

O classificador adaptável visa selecionar um subconjunto de indicadores mais informativos do status socioeconômico de cada domicílio. A entrevista adaptável inicia-se com a pergunta das quatro covariáveis, seguida da questão da renda familiar bruta mensal. Como a renda é um indicador contínuo, a probabilidade posterior de o domicílio pertencer ao estrato $s$ dada a renda $\mathbf{y}_{1}$ é dada por:

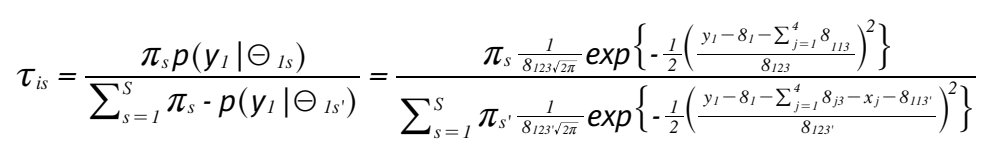

As respostas a essas cinco questões condicionam a seleção da próxima pergunta a ser feita ao entrevistado. Esse procedimento baseia-se na identificação de qual indicador restante produz maior redução de entropia de classificação do domicílio nos estratos socioeconômicos. A entropia esperada para o indicador $k$ depende do dado $y_{k}$ - que obviamente não se tem em mãos, pois a pergunta ainda não foi feita. Para estimar a entropia esperada para o indicador $k$, necessita-se primeiro calcular a probabilidade posterior de classificação do respondente - $\tilde{\tau}_{k s^{\prime}}$ - dada a resposta esperada a esse indicador. Para isso, integra-se a distribuição de frequências das respostas para esse indicador $\left(f\left(y_{k}\right)\right)$ :

$$
\tilde{\tau}_{k s}=\int \frac{\tau_{s p l}\left(y_{k} \mid \Theta_{k k}\right)}{\sum_{s=1}^{s} \tau_{k s} p\left(y_{k} \mid \Theta_{k s}\right)} f\left(y_{k}\right) d y_{k}
$$

0 indicador $k$, que produz a maior entropia esperada ( $\left.\sum_{s=1}^{7}-\tilde{\tau} k_{s} \ln \left(\tilde{\tau}_{k s}\right)\right)$, será a próxima pergunta a ser feita ao entre- vistado. Uma vez que os dados desse próximo indicador forem coletados, novas probabilidades de classificação são calculadas usando o mesmo procedimento descrito até atingir 15 indicadores que, somados à renda familiar e às quatro covariáveis, totalizam 20 indicadores mais adaptados ou pertinentes para a classificação socioeconômica desse específico domicílio $i$.

Os classificadores de verossimilhança condicional e bayesiano adaptável estão disponíveis no site www.pesquisasocioeconomica.com.br.

Por último, o novo classificador simplificado adotado pela ABEP (2013), construído por meio de regressão logística, compreende 15 indicadores, cujos pontos foram definidos pelo coeficiente de cada variável dummy selecionada (Tabela 6). Em função da soma obtida de pontos, classifica-se o domicílio no respectivo estrato socioeconômico (Tabela 7 ). Ressalte-se que esse classificador retrata uma classificação única para todo o 
Brasil, não levando em consideração a localização geográfica e composição familiar do consumidor.

Tabela 6. Novo classificador simplificado ABEP

\begin{tabular}{|c|c|c|c|c|c|}
\hline \multirow{2}{*}{ Indicadores } & \multicolumn{5}{|c|}{ Quantidade } \\
\hline & 0 & 1 & 2 & 3 & $4 \mathrm{ou}+$ \\
\hline Empregado doméstico & 0 & 3 & 7 & 10 & 13 \\
\hline Banheiro & 0 & 3 & 7 & 10 & 14 \\
\hline Automóvel & 0 & 3 & 5 & 8 & 11 \\
\hline Motocicleta & 0 & 1 & 3 & 3 & 3 \\
\hline Microcomputador & 0 & 3 & 6 & 8 & 11 \\
\hline DVD & 0 & 1 & 3 & 4 & 6 \\
\hline Lava-louça & 0 & 3 & 6 & 6 & 6 \\
\hline Geladeira & 0 & 2 & 3 & 5 & 5 \\
\hline Freezer & 0 & 2 & 4 & 6 & 6 \\
\hline Micro-ondas & 0 & 2 & 4 & 4 & 4 \\
\hline Lava-roupa & 0 & 2 & 4 & 6 & 6 \\
\hline Secadora de roupa & 0 & 2 & 2 & 2 & 2 \\
\hline Serviços públicos & & & & Não & Sim \\
\hline Água encanada & & & & 0 & 4 \\
\hline Rua pavimentada & & & & 0 & 2 \\
\hline
\end{tabular}

Escolaridade da pessoa de referência no domicílio

\begin{tabular}{l|l}
\hline Analfaberto/Fundamental I incompleto & 0 \\
\hline Fundamental I incompleto/Fundamental II incompleto & 1 \\
\hline Fundamental II incompleto/Ensino Médio incompleto & 2 \\
\hline Ensino Médio incompleto/Superior incompleto & 4 \\
\hline Superior completo & 7 \\
\hline
\end{tabular}

Nota. Adaptado de Associação Brasileira de Empresas de Pesquisa,2013.
Tabela 7. Classificação socioeconômica do domicílio segundo o critério ABEP simplificado

\begin{tabular}{c|c}
\hline Estrato & Pontos \\
\hline 1 & 43 ou mais \\
\hline 2 & 37 a 42 \\
\hline 3 & 26 a 36 \\
\hline 4 & 19 a 25 \\
\hline 5 & 15 a 18 \\
\hline 6 & 11 a 14 \\
\hline 7 & o a 10 \\
\hline
\end{tabular}

Nota. Adaptado de Associação Brasileira de Empresas de Pesquisa, 2013.

\section{ANÁLISE COMPARATIVA DE CLASSIFICADORES SOCIOECONÔMICOS}

Existem no Brasil duas bases de dados que poderiam ser utilizadas para a estratificação socioeconômica da sociedade brasileira: a PNAD e a POF, ambas gerenciadas pelo IBGE (2009). Na primeira, dados do imóvel, trabalho, estudo, renda e existência ou não (dado binário) de um conjunto de bens são declarados pelo entrevistado. Na segunda, mais analítica - selecionada para construção do novo critério de estratificação socioeconômica -, os dados coletados refletem o conceito de comprobabilidade, devendo-se comprovar os dados por registros feitos ou pela presença no domicílio. Essa pesquisa pode ser considerada um retrato fidedigno da sociedade brasileira em termos de características físicas do domicílio e acesso a utilidades públicas, composição familiar, educação, emprego e rendimentos de cada membro da família, aspectos das condições de vida da família, quantidade possuída de bens duráveis e montante consumido de bens e serviços, informação essa de enorme utilidade para entender o comportamento de como os domicílios alocam o orçamento familiar. 0 método amostral para a seleção dos domicílios - conglomerado de dois estágios - abrange todas as unidades federativas, e a amostra de 55.970 moradias é representativa do universo de 57.816.604 domicílios existentes no Brasil no período da pesquisa.

Para a construção do classificador assumido como benchmark para efeito de comparação (verossimilhança condicional), foram utilizadas 35 variáveis (Tabela 4), sendo sete demográficas (renda familiar corrente, anos de estudo do chefe da família, número de dormitórios, número de banheiros, tipo de abastecimento de água e de esgotamento sanitário e pavimentação), quantidade de empregados mensalistas e de 27 produtos de conforto doméstico. Foram consideradas, ainda, as quatro covariáveis mencionadas. Na Tabela 4, o número à direita de cada nome de item representa a quantidade existente dentro do domicílio. Por exemplo, televisão em cores tem quatro categorias, variando de o, 1, 2, 3 ou mais aparelhos no domicílio, e assim sucessivamente. 


\section{METODOLOGIA DE ANÁLISE E RESULTADOS}

Utilizamos a classificação obtida pelo classificador por verossimilhança condicional como a base de comparação, porque ela define os estratos socioeconômicos de acordo com o novo critério completo da ABEP. Isso foi feito dada a inexistência de um classificador benchmark que fosse a verdade objetiva. Nossa justificativa para utilizar como tal o classificador de verossimi-
Ihança é o fato de ele incorporar maior número de indicadores e ter embasamento teórico mais bem definido.

Para comparar as classificações obtidas pelos classificadores e critérios, utilizamos uma tabulação cruzada dos estratos socioeconômicos, calculando-se como métrica de precisão a média das máximas percentagens obtidas em cada um dos sete estratos definidos pelo classificador base (\% indicada em cada classificador na primeira coluna da Tabela 8 , calculada pela média ponderada dos números em negrito indicados nessa tabela).

\section{Tabela 8. Resultados da classificação obtidos por diferentes critérios e classificadores}

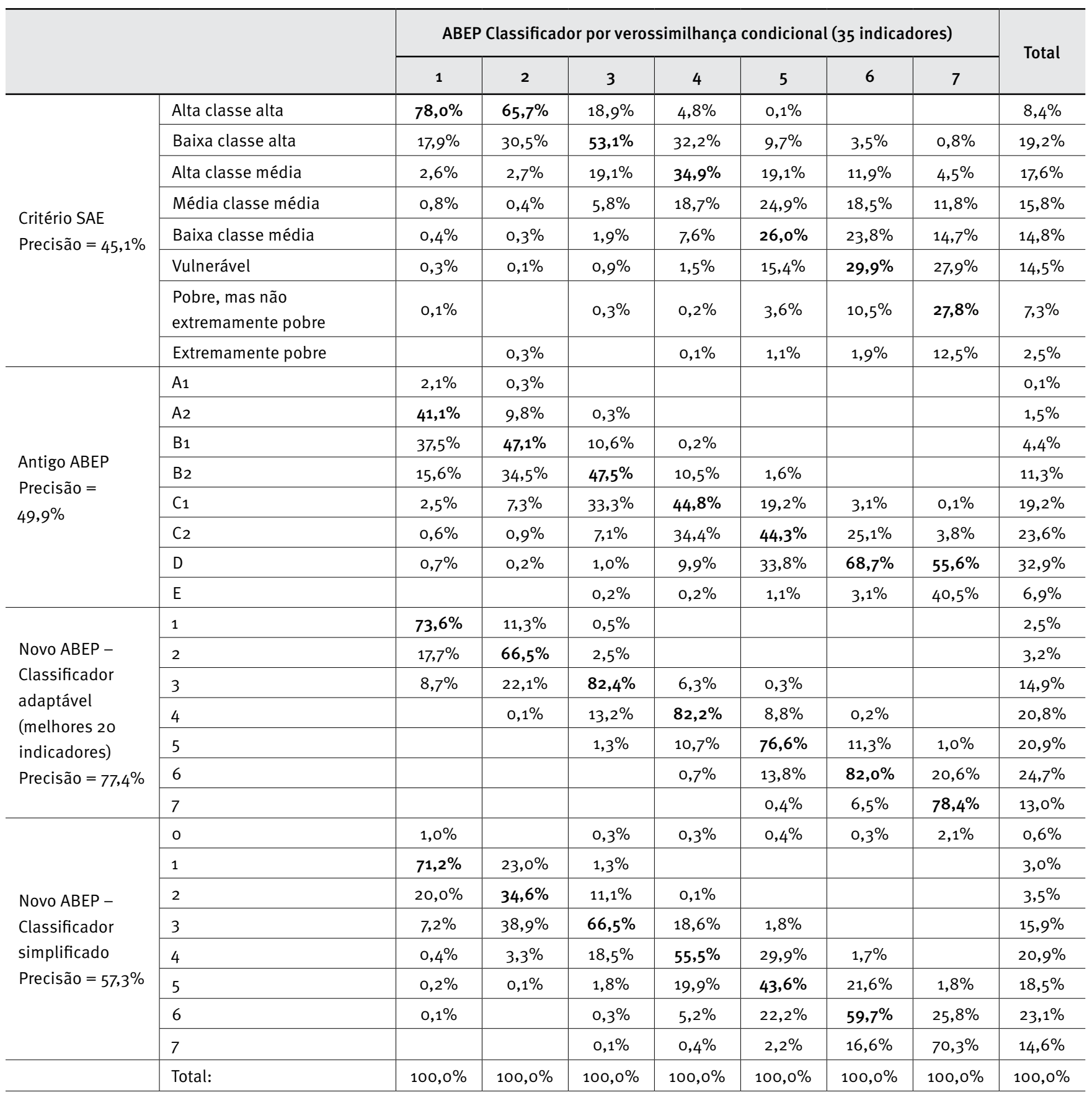


A comparação apresentada na Tabela 8 oferece alguns insights sobre as diferenças entre os critérios e classificadores com o ABEP novo. Por exemplo, devido ao fato de se basear exclusivamente na renda per capita dos domicílios, o critério SAE é o que menos tem em comum com o novo critério ABEP. A métrica de precisão é de 45,1\%, e a discrepância é mais acentuada nos estratos mais pobres. Observa-se que mais de $30 \%$ das famílias enquadradas no estrato 7 (de menor nível socioeconômico) pelo classificador de verossimilhança condicional foram alocadas na classe média pelo classificador SAE. De outra parte, a concordância entre o antigo e novo critério ABEP é de 49,9\%. Verifica-se, ainda, que, entre as duas opções de classificadores baseadas no novo critério $A B E P$, o classificador adaptável apresenta precisão de $77,4 \%$, embora utilize 20 (incluídas as quatro covariáveis) dos 39 indicadores do classificador de verossimilhança condicional. Pode-se notar que essa performance é superior à do classificador simplificado, mesmo utilizando um número semelhante de indicadores. Isso ocorre por duas razões. O classificador adaptável seleciona os indicadores mais informativos quanto ao status socioeconômico do domicílio, enquanto o critério simplificado utiliza o mesmo questionário para todos os entrevistados, utilizando um sistema de pontuação linear. Verifica-se, também, que o classificador simplificado não classificou 0,6\% dos domicílios, devido a dados faltantes, enquanto o classificador adaptável é imune a isso. Para efeito de uma análise mais condescendente, quando se considera a classe adjacente à classe mais provável, a precisão aumenta para 93,0\% e 82,3\% nos classificadores adaptável e simplificado, respectivamente, o que indicaria uma boa acurácia na classificação.

Contudo, para uma comparação mais relevante - sob o ponto de vista de marketing - utilizamos a classificação obtida pelos vários critérios e classificadores para explicar as variações de consumo entre os domicílios em 20 categorias de despesas (Tabela 9), utilizando um modelo multivariado linear generalizado (Green \& Silverman, 1994), onde o R-quadrado ajustado foi calculado utilizando somente a estratificação socioeconômica obtida de cada critério e classificador (preditor) para explicar o consumo em cada categoria, tendo em vista que o objetivo deste estudo centra-se precisamente na comparação da performance desses classificadores.

Tabela 9. Percentagem da variação no consumo explicado pelas estratificações socioeconômicas (R-quadrado ajustado)

\begin{tabular}{|c|c|c|c|c|c|}
\hline Categoria de consumo & SAE & ABEP antigo & Novo ABEP & $\begin{array}{l}\text { Novo ABEP } \\
\text { adaptável }\end{array}$ & $\begin{array}{l}\text { Novo ABEP } \\
\text { simplificado }\end{array}$ \\
\hline Alimentação no domicílio (mercearia, laticínio, carnes, frutas etc.) & $4 \%$ & $7 \%$ & $9 \%$ & $9 \%$ & $8 \%$ \\
\hline Alimentação fora do domicílio (bar, lanchonete, restaurante etc.) & $17 \%$ & $19 \%$ & $23 \%$ & $23 \%$ & $20 \%$ \\
\hline Bebidas (refrigerantes, sucos, destilados, cerveja etc.) & $4 \%$ & $5 \%$ & $6 \%$ & $6 \%$ & $5 \%$ \\
\hline Artigos de limpeza (sanitários, descartáveis etc.) & $2 \%$ & $3 \%$ & $4 \%$ & $4 \%$ & $4 \%$ \\
\hline $\begin{array}{l}\text { Produtos para manutenção da casa (decoração, cama, mesa, } \\
\text { banho, utensílios etc.) }\end{array}$ & $2 \%$ & $4 \%$ & $5 \%$ & $5 \%$ & $4 \%$ \\
\hline Eletrodomésticos (cozinha, som, vídeo, TV etc.) & $10 \%$ & $14 \%$ & $17 \%$ & $15 \%$ & $17 \%$ \\
\hline Vestuário (masculino, feminino e infantil) & $6 \%$ & $9 \%$ & $12 \%$ & $12 \%$ & $10 \%$ \\
\hline Cuidados pessoais (higiene, beleza etc.) & $7 \%$ & $11 \%$ & $14 \%$ & $13 \%$ & $12 \%$ \\
\hline Saúde e medicamentos (seguro, remédios etc.) & $12 \%$ & $12 \%$ & $16 \%$ & $16 \%$ & $13 \%$ \\
\hline Educação (mensalidade, livros, papelaria etc.) & $10 \%$ & $17 \%$ & $19 \%$ & $18 \%$ & $17 \%$ \\
\hline Viagens, recreação e cultura (eventos, cinema, CDs, viagens etc.) & $13 \%$ & $17 \%$ & $19 \%$ & $19 \%$ & $17 \%$ \\
\hline Fumo (tabaco e acessórios) & $0 \%$ & $1 \%$ & $1 \%$ & $1 \%$ & $1 \%$ \\
\hline Uso pessoal (ótica, relógio, joias, bolsas, cintos etc.) & $4 \%$ & $7 \%$ & $7 \%$ & $7 \%$ & $6 \%$ \\
\hline $\begin{array}{l}\text { Habitação e materiais de construção (aluguel, condomínio, } \\
\text { reforma etc.) }\end{array}$ & $25 \%$ & $28 \%$ & $34 \%$ & $35 \%$ & $32 \%$ \\
\hline Telefonia fixa e móvel (contas, aparelho e acessórios) & $30 \%$ & $40 \%$ & $46 \%$ & $44 \%$ & $44 \%$ \\
\hline $\begin{array}{l}\text { Transporte e manutenção de automóvel (ônibus, metrô, } \\
\text { combustível etc.) }\end{array}$ & $18 \%$ & $28 \%$ & $29 \%$ & $28 \%$ & $27 \%$ \\
\hline Impostos e despesas financeiras (juros, tarifas, taxas etc.) & $12 \%$ & $17 \%$ & $20 \%$ & $20 \%$ & $18 \%$ \\
\hline Serviços de utilidade pública (água, esgoto, eletricidade etc.) & $12 \%$ & $27 \%$ & $29 \%$ & $28 \%$ & $29 \%$ \\
\hline $\begin{array}{l}\text { Serviços pessoais e profissionais (manicure, cabeleireiro, } \\
\text { advogado etc.) }\end{array}$ & $20 \%$ & $26 \%$ & $30 \%$ & $29 \%$ & $28 \%$ \\
\hline Outras despesas (jogos, pensão, bancos etc.) & $11 \%$ & $9 \%$ & $13 \%$ & $14 \%$ & $10 \%$ \\
\hline
\end{tabular}


Os resultados mostram que a estratificação baseada unicamente na renda per capita (SAE) apresentou pior desempenho em relação às estratificações que utilizam mais indicadores socioeconômicos (nova e antiga ABEP) para explicar variações no consumo das famílias brasileiras. Nas 20 categorias de despesas, o novo critério da ABEP produz uma melhor explicação do consumo que os outros critérios, com pequenas variações entre o classificador por verossimilhança e o adaptável. Mesmo o ABEP antigo mostra performance superior ao critério SAE. 0 classificador simplificado em relação ao novo critério ABEP apresenta deterioração no poder explanatório em relação tanto ao classificador completo quanto ao adaptável.

À primeira vista, o poder explanatório de todos os critérios e classificadores parece baixo (variando de o\% a 46\%). Entretanto, deve-se levar em conta que há muitos outros fatores - não só a estratificação - que afetam o consumo; esses fatores também interagem com o status socioeconômico para determinar o nível de consumo do domicílio em cada categoria de bens e serviços. Como somente foi utilizado o estrato socioeconômico para explicar o consumo (porque nosso objetivo é comparar os classificadores), não se deve mostrar surpresa pelo baixo poder explanatório mostrado na Tabela 9. 0 mais importante é que os classificadores foram comparados nas mesmas circunstâncias.

Para a finalidade de marketing, a estratificação socioeconômica serve como base importante na segmentação do mercado (Wedel
\& Kamakura, 2002) e, por isso, é fundamental que a estratificação resulte em segmentos que sejam diferenciados em termos de consumo e na sua relevância para as empresas. Na Figura 1, comparam-se os três critérios (SAE, ABEP antigo e ABEP novo por verossimilhança condicional) em termos da magnitude de cada um dos seus estratos como segmentos de mercado em cada categoria de bens e serviços de consumo, utilizando-se, para isso, a base de dados da POF 2009. Para construir as Figuras 1, 2 e 3, os três classificadores foram aplicados aos dados dessa POF, tendo-se projetado as participações dos estratos na demanda de cada uma das respectivas categorias. Assim, olhando de baixo para cima em cada figura, visualizam-se as curvas da participação percentual acumulada no consumo total, partindo do estrato socioeconômico de nível mais elevado até o de menor nível. Dessa forma, a primeira curva de baixo para cima refere-se à participação do estrato 1 no consumo total de cada categoria de bem ou serviço. A segunda curva de baixo para cima refere-se à participação percentual acumulada dos estratos socioeconômicos $1 \mathrm{e}$ 2, e assim sucessivamente, até a última curva, que representa a participação do estrato 7. A diferença entre duas curvas corresponde à participação no consumo de um respectivo estrato socioeconômico. Podemos observar, nas três figuras, que os estratos 1 e 2 representam uma participação significativamente mais elevada no consumo total de cada categoria que a sua participação no total de domicílios, ocorrendo o oposto com os estratos de menor nível socioeconômico.

Figura 1. Segmentos de mercado definidos pela estratificação socioeconômica da SAE segundo projeções pela POF 2009

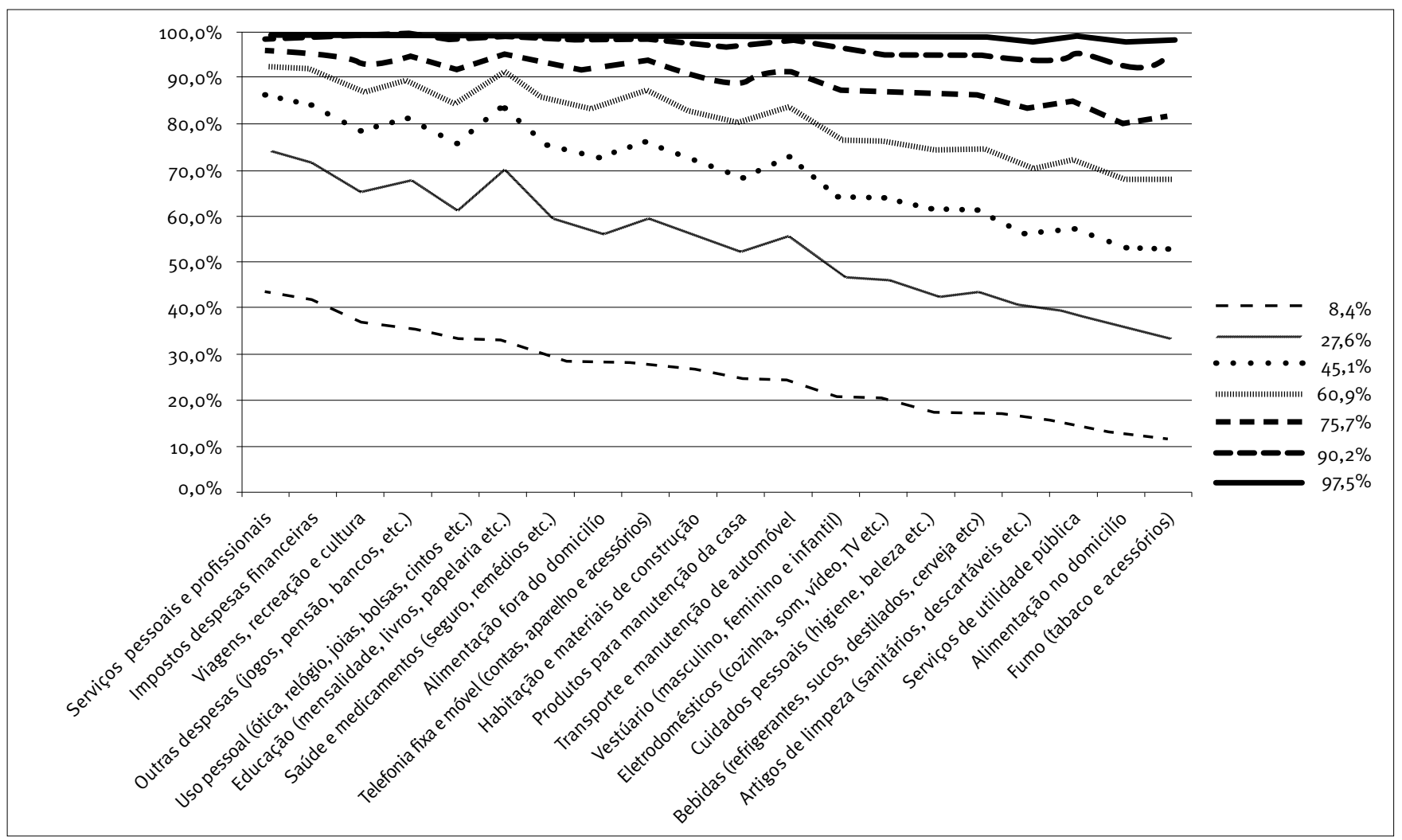


A Figura 1 mostra que a segmentação pelo critério SAE é extrema, com alta percentagem (acima de 30\%) do consumo não essencial concentrada no segmento mais abastado $(8,4 \%$ dos domicílios); mais que a metade desse consumo é observada só nos dois segmentos mais ricos (27,6\% dos domicílios); os três últimos segmentos de menor poder aquisitivo representam uma parcela insignificante de qualquer dos 20 mercados considerados. Depreende-se, assim, que o critério SAE tende a classificar uma maior percentagem de domicílios nas classes mais altas diante do novo critério $A B E P$, com uma participação expressiva desses estratos no consumo total de cada categoria de bem ou serviço.
O oposto ocorre com o critério ABEP antigo (Figura 2), que classifica uma pequena percentagem $(6,0 \%)$ dos domicílios nos três segmentos mais abastados da sociedade brasileira e grande concentração nos estratos mais pobres. Os três primeiros segmentos respondem por entre $9 \%$ e menos que $40 \%$ do consumo total em todas as 20 categorias de bens e serviços. Observa-se que, mesmo nas categorias de despesas não essenciais, os segmentos nos dois extremos (mais rico e mais pobre) são insignificantes para todos os 20 mercados estudados.

\section{Figura 2. Segmentos de mercado definidos pela antiga estratificação socioeconômica da ABEP segundo projeções pela POF 2009}

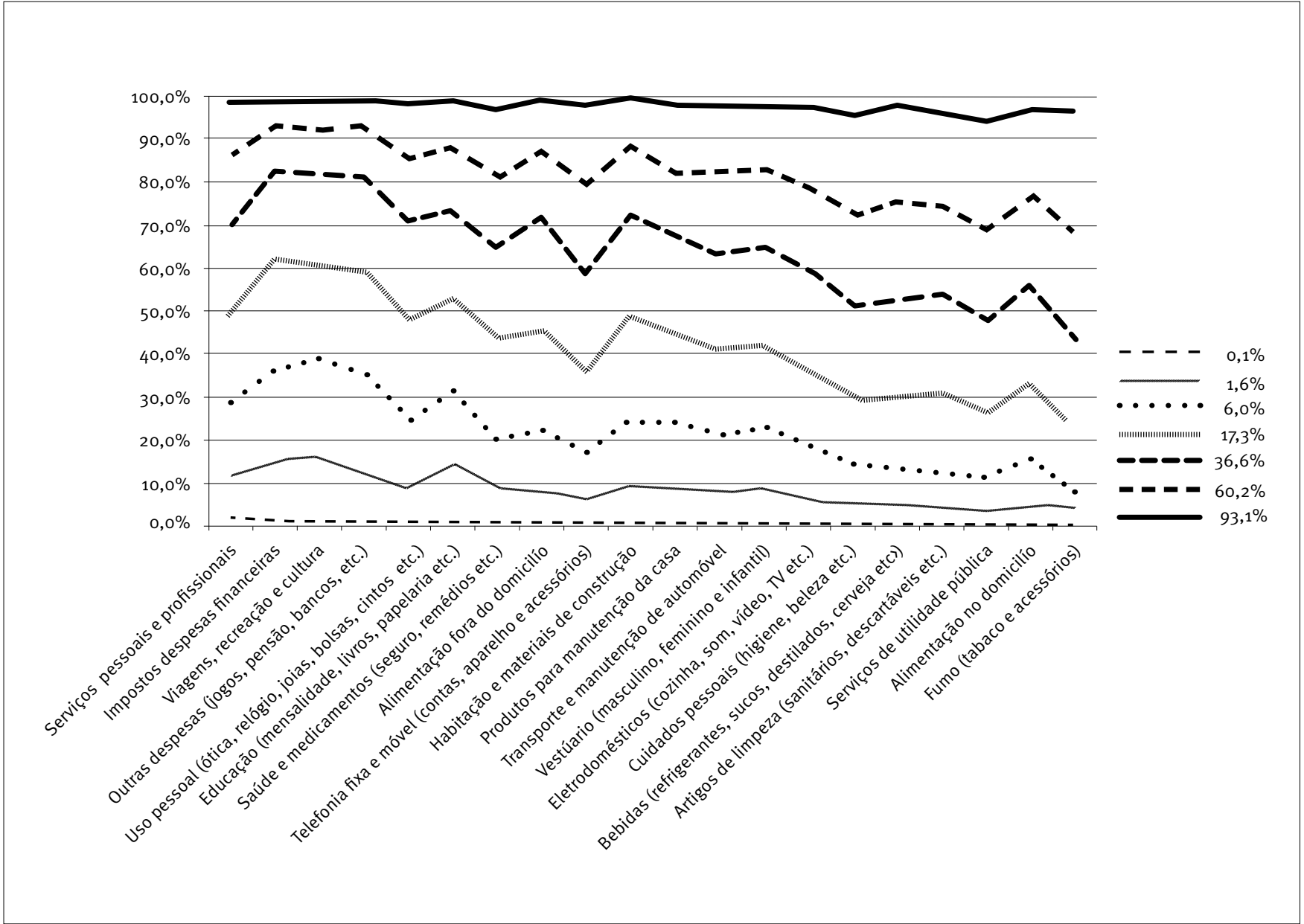

O novo critério da ABEP de verossimilhança condicional (Figura 3) resulta numa segmentação mais bem distribuída dos mercados em todas as categorias de bens e serviços, embora mostre uma alta concentração no consumo de produtos não essenciais, que seria reflexo das condições do mercado brasileiro, notadamente em termos de distribuição de renda. Verifica-se, pelos resultados, que os três segmentos mais abastados (21,5\% dos domicílios) representam de $30 \%$ a $70 \%$ do consumo de todos os 20 mercados considerados. 
Figura 3. Segmentos de mercado definidos pela nova estratificação socioeconômica da ABEP segundo projeções pela POF 2009

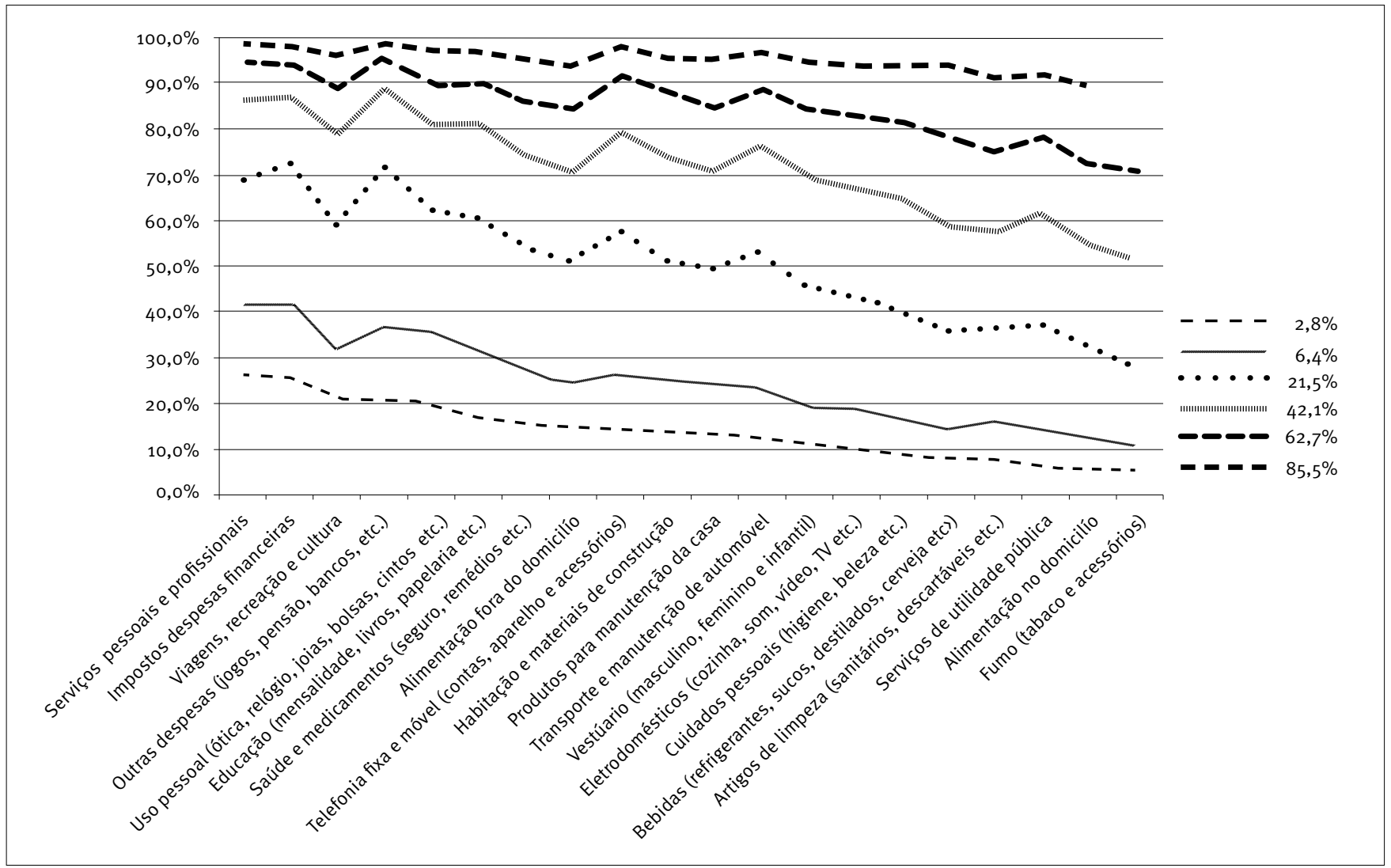

\section{CONCLUSÕES E IMPLICAÇÕES}

Segmentar mercados é uma prática imperativa na gestão de marketing das empresas. Decorre do reconhecimento de que cada segmento tem necessidades distintas. Uma das formas de segmentação é por meio do status socioeconômico das famílias, dado que necessidades costumam ser diferentes em função de maior ou menor grau desse status. Produtos, serviços e marcas são consumidos em quantidade e qualidade variadas segundo o nível socioeconômico. Empresas colocam à venda produtos e serviços que visam atender às necessidades de cada segmento; agências implementam campanhas de comunicação de modo a persuadir segmentos de consumidores de que certos produtos ou marcas podem atender às suas necessidades; veículos de comunicação procuram informar melhor seus leitores, ouvintes ou telespectadores objetivando retê-los na marca. Para que isso funcione adequadamente, é fundamental colocar uma questão: Como identificar e mensurar o tamanho e perfil de classes socioeconômicas de maneira fidedigna, válida, confiável? A análise de como dividir uma sociedade em classes socioeconômicas é um desafio conceitual e metodológico. Há um descompasso entre o que propõe a teoria e o que se executa, como demonstrado por Kamakura e Mazzon (2013a, 2013b).

No Brasil, existem três principais critérios de estratificação socioeconômica e cinco classificadores de domicílios em uma dada classe: SAE, ABEP antigo e três novos da ABEP, com vigência a partir de 2015: de verossimilhança condicional, bayesiano adaptável e simplificado. As características conceituais e metodológicas de cada um deles evidenciam que o de máxima verossimilhança, seguido do bayesiano adaptável, é o que melhor atenderia aos pesquisadores acadêmicos e às gerências de marketing das empresas. Como critério, eles são conceitualmente mais bem fundamentados, e, como classificadores, são operacionalmente mais flexíveis e precisos para estratificar a sociedade brasileira considerando o conceito de renda permanente, ou riqueza da família, condição que define a capacidade de consumo. Essas características tornam esses dois classificadores os mais adequados para efeito de utilização em marketing.

Tomando o classificador de verossimilhança condicional como benchmark, fizemos uma comparação cruzada das classificações dos estratos socioeconômicos de cada um dos classificadores. Os resultados mostraram que a maior precisão, 
comparativamente ao classificador base, foi alcançada pelo classificador adaptável (77,4\%), seguido do simplificado (57,3\%), ABEP antigo (49,9\%) e SAE (45,1\%). Uma segunda avaliação foi realizada, tomando por base o quanto cada classificador explica das variações no montante consumido de bens e serviços entre estratos socioeconômicos. A comparação do poder explanatório dos cinco classificadores para 20 categorias de bens e serviços mostrou que a melhor performance correspondeu ao classificador de verossimilhança condicional, seguido pelo bayesiano adaptável, simplificado, ABEP antigo e SAE. Essa ordem foi confirmada pelas duas formas de avaliação.

Como implicação, por meio desses novos classificadores, institutos de pesquisa, gestores de marketing, professores, pesquisadores e estudantes em geral poderão classificar, de maneira mais fidedigna e confiável, amostras de domicílios ou consumidores em um dos sete estratos socioeconômicos em que se divide a sociedade brasileira. 0 novo critério ABEP encontra forte sustentação teórica e metodológica, tendo-se mostrado consistente em termos de validação com as análises realizadas para as categorias de consumo analisadas. Por meio dos classificadores ABEP de verossimilhança condicional e bayesiano adaptável, é possível utilizar uma importante inovação: considerar, na classificação de um domicílio, diferenças regionais, de localização e da composição das famílias brasileiras.

Numa sociedade dinâmica como a brasileira, é de esperar que a estratificação socioeconômica mude num período relativamente curto e, portanto, a definição dos estratos deve acompanhar essa dinâmica. Por outro lado, esse tipo de segmentação da população de domicílios deve ser feito com base em dados fidedignos de uma amostra representativa do total da população do País, como são os dados da POF coletados pelo IBGE. Consequentemente, é necessário revisar o critério de estratificação tão logo novos dados de consumo e indicadores socioeconômicos da POF sejam disponibilizados.

\section{REFERÊNCIAS}

Associação Brasileira de Empresas de Pesquisa. (2011). Critério de classificação econômica Brasil. Recuperado de http://www.abep. $\mathrm{org} /$ novo/Content.aspex?ContentID=301.

Associação Brasileira de Empresas de Pesquisa. (2013). Critério Brasil 2015. Recuperado de http://www.abep.org/download.

Bass, F. M., Pessemier, E. A., \& Tigert, D. J. (1969). A taxonomy of magazine readership applied to problems in marketing strategy and media selection. Journal of Business, 42(3), 337-363.

Bauer, R., Cunningham, S. M., \& Wortzel, L. H. (1965). The marketing dilemma of negroes. Journal of Marketing, 29(3), 1-6. doi:10.2307/1248537
Blank, R. M. (2010). Middle class in America. US Department of Commerce Economics and Statistics Division.

Bollen, K. A., Glanville, J. L., \& Stecklov, G. (2001). Socioeconomic status and class in studies of fertility and health in developing countries. Annual Review of Sociology, 27, 153-185. doi:10.1146/annurev. soc.27.1.153

Campello, T., \& Neri, M. C. (Org.). (2013). Programa Bolsa Família: Uma década de inclusão e cidadania. Recuperado de

http://www.ipea.gov.br/portal/index.php?option=com content $\&$ view $=$ article $\&$ id $=20408$

Corrales, B., Barbarena, M., \& Schmeichel, N. (2006). Latin American profile, demographics and socio economic strata. Research paper. ESOMAR - European Society for Opinion and Marketing Research.

Cui, A., \& Song, K. (2009). Understanding China's middle class. China Business Review. Recuperado de http://www.chinabusinessreview. com/

Dahl, D. W., \& Moreau, P. (2007,). Thinking inside the box: Why consumers enjoy constrained creative experiences. Journal of Marketing Research, 44(3), 357-369. doi:10.1509/jmkr.44.3.357

Deaton, A., \& Muellbauer, J. (2009). Economics and consumer behavior. New York: Cambridge University Press.

Frank, R. E., \& Massy, W. F. (1965). Market segmentation and the effectiveness of a brand's price and dealing policies. Journal of Business, 38(2), 186-200.

Friedman, M. (1957). A theory of the consumption function. Princeton: Princeton University Press.

Green, P. J., \& Silverman, B. W. (1994). Nonparametric regression and generalized linear models. London: Chapman and Hall.

Instituto Brasileiro de Geografia e Estatística. (2009). Pesquisa de orçamentos familiares. Recuperado de http://www.ibge.gov. br/home/estatistica/pesquisas/pesquisa_resultados.php?id_ pesquisa $=25$

Kamakura, W. A., \& Mazzon, J. A. (2013a). Estratificação socioeconômica e consumo no Brasil. São Paulo: Blucher.

Kamakura, W. A., \& Mazzon, J. A. (2013b). Socioeconomic status and consumption in an emerging economy. International Journal of Research in Marketing, 30(1), 4-18. doi:10.1016/j. ijresmar.2011.12.001

Mittal, B., Holbrook, M., Sharon, B., Raghubir, P., \& Woodside, A. (2008). Consumer behavior: How human think, feel, and act in the marketplace. Cincinatti, Ohio: Open Mentis.

Neri, M. C. (2011). A nova classe média: O lado brilhante da base da pirâmide. Rio de Janeiro: Saraiva.

Rich, S. U., \& Jain, S. C. (1968). Social class and life cycle as predictors of shopping behavior. Journal of Marketing Research, 5(1), 41-49. doi:10.2307/3149792

Rucker, D. D., \& Galinsky, A. D. (2008). Desire to acquire: Powerlessness and compensatory consumption. Journal of Consumer Research, 35(2), 257-267. doi:10.1086/588569

Saegert, S. C., Adler, N. E., Bullock, H. E., Cauce, A. M., Liu, W. M., \& Wyche, K. F. (2006). Report of the APA task force on socioeconomic status. American Psychological Association, Washington.

Schmeichel, N., Corrales, B., \& Barberena, M. (1999). Latin American profile, demographics and socio economic strata. Research paper. Latin American Conference, Esomar - European Society for Opinion and Marketing Research. 
Secretaria de Assuntos Estratégicos, Presidência da República. (2012). Relatório de definição da classe média no Brasil. Recuperado de

http://www.sae.gov.br/documentos/publicacoes/relatorio-dedefinicao-da-classe-media-no-brasil/

Senauer, B., \& Goetz, L. (2003). The growing middle class in developing countries and the market for high-value food products [Working Paper 03-02]. The Food Industry Center, University of Minnesota.

Steenkamp, J. B. E. M., Jong, M. G., \& Baumgartner, H. (2010). Socially desirable response tendencies in survey research. Journal of Marketing Research, 47(2), 199-214. doi:10.1509/jmkr.47.2.199

Urquijo, J., \& Lobl, R. (2003). Socioeconomic levels: Differences vs. similarities. Research paper. ESOMAR - European Society for Opinion and Market Research.
Vermunt, J. K., \& Magidson, J. (2010). Latent gold users's guide. Belmont: Satistical Innovations, Inc.

Wedel, M., \& Kamakura, W. A. (2001). Marketing segmentation: Conceptual and methodological foundations. Boston: Kluwer Academic Publishers.

Wedel, M., \& Kamakura, W. A. (2002). Introduction to the special issue on market segmentation. International Journal of Research in Marketing, 19(3), 181-183. doi:10.1016/S0167-8116(02)00075-7

Williams, T. G. (2002). Social class influences on purchase evaluation criteria. Journal of Consumer Marketing, 19(3), 249-276. doi:10.1108/07363760210426067 